\title{
TRANSMISSÃO DE PREÇOS NO MERCADO INTERNACIONAL DE CAFÉ ROBUSTA ${ }^{1}$
}

\author{
Dênis Antônio da Cunha ${ }^{2}$ \\ Marcelo José Braga \\ Antônio Carvalho Campos ${ }^{4}$ \\ Luciany Lima Fernandes ${ }^{5}$
}

\begin{abstract}
Resumo: O mercado de café robusta tem experimentado mudanças caracterizadas pelo crescimento da demanda e pela confirmação do Vietnã como maior produtor e exportador, ultrapassando tradicionais produtores, como a Indonésia. Essas alterações motivaram a análise da integração entre os preços internacionais e os principais mercados dessa commodity: Vietnã, Brasil, Indonésia e Índia. Foi testada a hipótese de que o Vietnã transmite choques de preços aos demais mercados. Analiticamente, utilizou-se a análise de co-integração e o modelo VEC. Constatou-se que, no período de 1988 a 2005, o preço externo e os do Vietnã, Brasil e Indonésia foram integrados; o preço da Índia foi influenciado por fatores que não são comuns aos demais países. Não houve perfeita integração e o Vietnã, embora importante, não foi o mercado mais interdependente.
\end{abstract}

Palavras-chave: Café robusta, transmissão de preços, integração de mercado, VEC.

Recebido em: 25/01/08. Aceito em: 04/04/08.

Estudante de mestrado do Programa de Pós-Graduação em Economia Aplicada do Departamento de Economia Rural da Universidade Federal de Viçosa - UFV. E-mail: denisufv@gmail.com

3 Doutor em Economia Aplicada. Prof. Associado do Departamento de Economia Rural da Universidade Federal de Viçosa - UFV.E-mail: mibraga@ufv.br

4 Ph.D. em Economia Agrícola. Prof. Titular, Departamento de Economia Rural da Universidade Federal de Viçosa-UFV.E-mail: accampos@ufv.br

5 Estudante de mestrado do Programa de Pós-Graduação em Economia Aplicada do Departamento de Economia Rural - UFV. E-mail: lucianyufv@ yahoo.com.br 


\section{Introdução}

O café é um dos produtos agrícolas de maior dinamismo comercial e desempenha importante papel na economia mundial, movimentando, anualmente, cerca de US\$ 70 bilhões. É um produto estratégico para a economia de muitos países em desenvolvimento das Américas, Ásia e África. Existem várias espécies, mas as comercialmente relevantes são a arábica e a robusta (ou conillon). Embora a primeira seja a mais comercializada e valorizada no mercado internacional, nos últimos anos, a demanda do robusta tem aumentado.

A espécie robusta corresponde a cerca de um terço do café produzido mundialmente, possui trato mais rude, maior resistência a pragas e menor custo de produção. É bastante cultivada no sudoeste da Ásia e no continente africano; na América do Sul, somente o Brasil e o Equador a produzem de modo significativo. É utilizada, basicamente, na produção de café solúvel e expresso, e como complemento de blends compostos por grãos mais finos (Ponte, 2001).

Os preços mais baixos e a maior utilização de café robusta na elaboração de blends pelas companhias processadoras do setor cafeeiro têm contribuído para um crescimento de suas exportações maior do que as de arábica. $\mathrm{O}$ aumento da importância dessa variedade no comércio internacional também se deve à expansão do consumo de café solúvel em países da Ásia e do leste europeu.

O Vietnã, maior produtor e exportador de café robusta, tem grande importância nesse cenário. Sua produção, que conta com grandes índices de produtividade (cerca de 32 sacas por hectare, o que representa quase o dobro da produção de conillon no Brasil), destina-se, basicamente, à exportação (mais de 90\%). A expansão do país no mercado é um processo recente e data do início da década de 90. É importante ressaltar que grande parte do crescimento de sua participação no comércio internacional deve-se aos seus baixos custos de produção (Saes; Miranda, 
2007a). A Figura 1 apresenta a evolução da produção vietnamita e de outros importantes produtores mundiais.

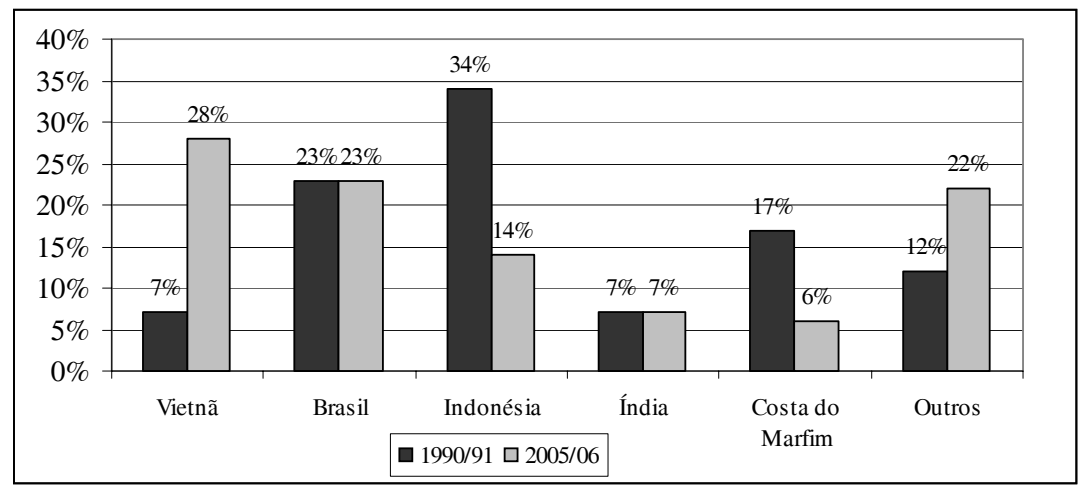

Figura 1 - Produção mundial de café robusta, comparação entre 1990/ 91 e 2005/06.

Fonte: Elaborado pelos autores a partir dos dados do United States Department of Agriculture (USDA, 2007).

A Ásia e o Brasil vêm substituindo a África no fornecimento de robusta para o mercado internacional. Em 2007, conforme dados do USDA (2007), Vietnã, Brasil, Indonésia e Índia, juntos, responderam por cerca de $72 \%$ da produção e $78 \%$ das exportações dessa especialidade. À exceção do Brasil, no qual apenas um terço da produção se refere à espécie robusta, os demais países são especializados nesse tipo de café. Na produção indiana, a proporção é de aproximadamente $60 \%$; na Indonésia, varia de $85 \%$ a $90 \%$; enquanto a vietnamita ultrapassa $95 \%$.

Seu cultivo, processamento, comércio, transporte e marketing geram emprego e renda para grande parcela da população, tendo influência significativa na economia de muitos dos países que o produzem.

No Vietnã, o café foi escolhido pelo governo, em meados dos anos 90, como um meio de trazer prosperidade ao meio rural. A produção da espécie robusta foi então desenvolvida em sistema intensivo, com alta densidade de plantio, largo uso de fertilizantes minerais e irrigação, e 
sem árvores para sombreamento. Como resultado, o país aumentou sua produção de pouco mais de um milhão de sacas, em 1990, para cerca de 17 milhões, em 2007, e tornou-se o maior exportador dessa variedade. Atualmente, o café robusta é o segundo produto de exportação do país (o arroz é o primeiro), e 300 mil pequenos agricultores são responsáveis pela totalidade da produção (em épocas de colheita, o setor chega a empregar 800 mil pessoas) (Saes; Miranda, 2007a).

Na Indonésia e Índia, a produção e exportação de café robusta assumem grande importância na geração de renda da população rural, notadamente para a agricultura familiar. $\mathrm{Na}$ Indonésia, $95 \%$ da produção é realizada em propriedades com menos de cinco hectares. Já na Índia, o café gera cerca de 550 mil empregos diretos, e a subsistência de outros cinco milhões de trabalhadores está ligada, indiretamente, a essa cadeia produtiva.

No Brasil, o café robusta não tem a mesma expressividade que nos países citados anteriormente. Ainda assim, gera renda e milhares de empregos nas regiões em que é produzido (principalmente Espírito Santo e Rondônia). Sua importância também está relacionada com o fornecimento de matéria-prima para a indústria processadora de café solúvel, cuja produção é, em grande parte, voltada para a exportação.

Dada a crescente importância do tipo robusta no comércio internacional de café, juntamente com a ascensão do Vietnã como maior produtor e exportador, há necessidade de analisar como tem sido a dinâmica de preços nesse setor. Em outras palavras, torna-se importante verificar se os principais mercados de café robusta são integrados e, caso sejam, se o Vietnã é importante na transmissão de choques de preços entre eles.

Conforme Nogueira (2005), o mercado de café constitui-se de uma rede de produtores, processadores, traders e consumidores que se influenciam mutuamente. Tais influências recíprocas respeitam padrões decorrentes das relações de mercado, podendo refletir na integração e, portanto, no grau de eficiência com que funciona. 
Dênis Antônio da Cunha, Marcelo José Braga,

Antônio Carvalho Campos \& Luciany Lima Fernandes

A integração é benéfica na medida em que, segundo Goodwin e Schroeder (1991), mercados integrados contêm informações mais precisas e ajustam-se, de modo mais rápido, às mudanças na economia. Além disso, favorecem a especialização e as decisões de comercialização dos produtores, contribuindo para a movimentação eficiente de produtos.

A literatura de integração de mercados aborda, principalmente, a questão de os preços em localidades distintas serem, ou não, correlacionados. Assim, mercados integrados são aqueles em os preços praticados em cada localidade respondem, direta ou indiretamente, não apenas às suas próprias ofertas e demandas, mas também às condições de outras regiões (Pereira, 2005).

Nessa perspectiva, a análise da integração dos mercados internacionais de café é importante, já que permite melhor entendimento do processo de formação de preços nesse setor. Nogueira (2005) fez um detalhado estudo acerca da integração dos mercados de café arábica e robusta brasileiros, nacional e internacionalmente; não obstante, não analisou a integração entre regiões específicas, lacuna que o presente estudo procurou preencher. Assim, pretende-se verificar se os principais mercados de café robusta são integrados, ou seja, se apresentam relação de equilíbrio no longo prazo.

O objetivo geral deste estudo, portanto, foi analisar as relações existentes entre os preços pagos aos produtores do Brasil, Vietnã, Indonésia e Índia e o preço internacional, do qual as cotações da bolsa de Londres, NYSE EURONEXT (anteriormente London International Financial Futures and Options Exchange - LIFFE) são referência, dado que esta é a principal bolsa mundial que comercializa contratos futuros dessa commodity.

Além desta introdução, o trabalho está dividido em quatro seções. $\mathrm{Na}$ segunda, são apresentados aspectos teóricos relacionados com integração de mercados; na terceira, a metodologia utilizada; na quarta, os resultados obtidos; e na quinta, as principais conclusões. 


\section{Integração de mercados}

A integração espacial de mercados refere-se à interdependência dos preços em diferentes regiões ao longo do tempo. Segundo GonzálezRivera e Helfand (2001), para que um conjunto de localidades forme um mercado integrado, elas devem comercializar a mesma commodity e compartilhar informações semelhantes no longo prazo. Formalmente, um mercado com $n$ localidades, geograficamente distintas, será considerado integrado se duas condições forem satisfeitas:

(i) deve existir um fluxo físico de bens, direta ou indiretamente, que conecte as $n$ regiões; e

(ii) todas as localidades devem ter um vetor de preços, , que possa ser decomposto em um componente permanente, ou de longo prazo, que será o fator integrador do mercado, e um componente transitório, ou de curto prazo.

Para Fakler e Goodwin (2001), a formação de preços entre as regiões de um mercado integrado sofrerá influência não apenas das condições de oferta e demanda locais, mas também das condições das demais localidades. Dessa forma, a integração espacial é uma medida do grau em que os choques de demanda e oferta que surgem numa região são transmitidos a outra. Essa proposição é representada pela razão de transmissão de preços, $R i j$, associada a um choque hipotético na região $i, \varepsilon i$ (por exemplo, um excesso de oferta):

em que representa a variação infinitesimal do choque econômico que modifica o preço no bem na região $j$, enquanto 
Dênis Antônio da Cunha, Marcelo José Braga, Antônio Carvalho Campos \& Luciany Lima Fernandes

a variação infinitesimal do choque que altera o preço da região $i$. Se $R_{A B}$ for igual à unidade, uma mudança no preço de $i$ será transmitida na mesma intensidade a $j$ e as duas localidades serão perfeitamente integradas.

Nesse sentido, a movimentação conjunta de preços é uma condição para a integração e indica que ela não depende exclusivamente da arbitragem, sendo, portanto, um conceito diferente da Lei do Preço Único 6 . Para Faminow e Benson (1990), a integração é o processo pelo qual ocorre a interdependência de preços. Não é necessário que duas ou mais regiões tenham comércio direto para que sejam integradas. As alterações de preço podem ser transmitidas indiretamente por uma rede de comércio; e duas localidades, $i$ e $j$, produtoras e exportadoras de uma commodity, podem estar fortemente integradas devido às relações comerciais comuns com uma terceira região $y$.

\section{Modelo analítico}

Análises de integração de mercados que utilizam séries temporais pressupõem que elas sejam formadas por processos estocásticos que não sofrem mudanças ao longo do tempo. Séries que apresentam essa característica são ditas estacionárias. Segundo Enders (1995), um processo estocástico será fracamente estacionário se sua média e variância forem constantes ao longo do tempo e se o valor da co-variância entre dois períodos de tempo depender apenas da defasagem entre eles, e não do período efetivo em que for calculada.

\footnotetext{
6 A Lei do Preço Único admite que mercados concorrenciais, ligados por comércio e arbitragem, livres de custos de transação e barreiras oficiais às trocas, terão um preço comum e único para produtos homogêneos. Dessa forma, no caso de mercados perfeitamente integrados, em que a variação no preço de uma região é transmitida de maneira completa à outra, os conceitos são equivalentes (Krugman; Obstfeld, 2005).
} 
Embora grande parte das séries econômicas seja não-estacionária, elas podem ser diferenciadas uma ou duas vezes, tornando-se estacionárias. Se uma série for não-estacionária em nível, mas estacionária em primeira diferença, dir-se-á que é integrada de ordem um, I(1).

Dessa forma, o procedimento para realização do trabalho consistiu, primeiro, em analisar a estacionaridade das séries, por meio de testes de raiz unitária ${ }^{7}$.

Para verificar se os preços de diferentes localidades possuem tendência semelhante de comportamento, ou seja, se compartilham um fator integrador comum, considera-se, inicialmente, um vetor de preços logaritmizados $\left(P_{t}\right)$ de uma commodity, de ordem $(k \times 1)$, integrado de ordem um, I( 1$)$ (González-Rivera; Helfand, 2001):

$P_{t}=\left\{p_{1 t}, p_{2 t}, \ldots, p_{k t}\right\}$

em que $p_{i t}$ é o logaritmo do preço da commodity no mercado $i$, no tempo $t$.

Já que $P t$ é $I(1)$, pode ser decomposto em dois componentes, um permanente e outro provisório, isto é,

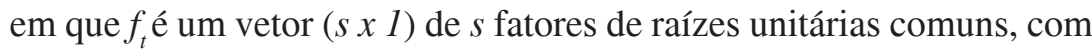
$s<k$ e $\widetilde{P}_{t}$ é um vetor de componentes estacionários [I(O)], de ordem

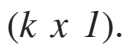

Por serem bastante conhecidos na literatura de séries temporais, os procedimentos de estimação dos testes de raiz unitária não foram apresentados. Entretanto, as especificações econométricas podem ser obtidas em Enders (1995). 
Dênis Antônio da Cunha, Marcelo José Braga,

Antônio Carvalho Campos \& Luciany Lima Fernandes

Os elementos de $P_{t}$ podem ser explicados por uma combinação linear de um número menor de fatores comuns $I(1), f_{j t}$ (componentes permanentes)

e um componente transitório $I(0)$, por exemplo,

Admite-se que, no longo prazo, as variáveis $p_{i t}$ movam-se conjuntamente, compartilhando a mesma tendência estocástica.

A relação (3) é chamada de representação comum e somente existirá se houver $(k-s)$ vetores de co-integração entre os elementos do vetor $P_{t}$ (no caso deste estudo, as séries logaritmizadas de preços de café robusta do Vietnã, Brasil, Indonésia e Índia). Dessa forma, se houver $k$ séries de preços, poderão existir $r$ vetores de co-integração e $s$ tendências (fatores) comuns, de modo que $r+s=k$. Um mercado integrado, portanto, terá $s$ $=1$, ou seja, as localidades compartilharão a mesma informação de longo prazo.

Pode-se reescrever (3) da seguinte forma:

$$
\begin{aligned}
p_{i t}= & \sum_{j=1}^{s} a_{i j} f_{i t}+\tilde{p}_{i t} \\
& p_{i t}=a_{i 1} f_{1 t}+\tilde{p}_{i t}, \operatorname{com} i=1, \ldots, k .
\end{aligned}
$$

Pela descrição anterior, conclui-se que a busca de um único fator integrador comum entre as séries de preços é o mesmo que procurar $(k$ -1 ) vetores de co-integração. A determinação das localidades que possuem essa característica foi realizada numa versão reparametrizada de um vetor de correção de erros (VEC), com $n$ defasagens, pelo procedimento de Johansen (1991):

$$
\Delta P_{t}=\mu+\Gamma_{1} \Delta P_{t-1}+\ldots+\Gamma_{n-1} \Delta P_{t-n+1}+\Pi P_{t-1}+e_{t},
$$

em que $P_{t}$ é um vetor $(k \times 1)$ de variáveis estocásticas; $e_{t}$, um vetor $(k x$ $1)$ de erros identicamente e independentemente distribuídos; e $\Pi$, uma matriz $\left(k x k\right.$ ) de posto $r<k$, definida por $\Pi=\alpha \beta^{T}$. As matrizes $\alpha$ e $\beta$ são de ordem $(k \times r)$, e $r$ é o posto da matriz $\Pi$, que equivale ao número 
de vetores de co-integração linearmente independentes, que, por sua vez, é igual ao número de raízes características, $\lambda$, estatisticamente diferentes de zero.

A matriz $\alpha$ indica a velocidade do ajustamento a um desequilíbrio qualquer e à estrutura espacial do modelo. Se todos os seus elementos forem estatisticamente significativos, ter-se-á um padrão de comportamento em que haverá extrema interdependência das localidades. A matriz $\beta$, chamada matriz de co-integração, caracteriza as relações que ocorrerão entre as variáveis no equilíbrio de longo prazo, ou seja, como cada variável co-integrada fará o sistema convergir, após um choque, em direção ao equilíbrio no longo prazo.

Há dois testes de razão de verossimilhança para identificar o número de vetores de co-integração, propostos por Johansen e Juselius (1990): teste do traço e do máximo autovalor.

$$
\lambda_{\text {max }}=-T \ln \left(1-\lambda_{v+1}\right),
$$

em que $T$ é o número de observações usadas no ajustamento; e $\lambda_{i}$, a iésima raiz característica.

O teste do traço verifica a hipótese de que existem, no máximo, $r$ vetores de co-integração $\left(H^{0}=r \leq r^{0}\right.$ contra $\left.H^{a}=r>r_{0}\right)$. O teste de máximo autovalor $(\lambda M A X)$, por sua vez, testa a hipótese nula de que há $r$ vetores de co-integração contra a hipótese alternativa de que há $(r+1)$.

Para que as localidades sejam integradas (pares co-integrados), é preciso que exista $(k-1)$ vetores de co-integração. Dessa forma, a determinação das regiões que pertencem a um mesmo mercado deverá ser iniciada com o conjunto total de localidade, $k$, e testar a existência da condição acima. 
Dênis Antônio da Cunha, Marcelo José Braga, Antônio Carvalho Campos \& Luciany Lima Fernandes

Se os testes indicarem um número de vetores de co-integração menor que , é preciso identificar o(s) preço(s) que deverá(ão) ser retirado(s) do sistema. Para isso, implementa-se um procedimento de exclusão seqüencial que se inicia com um núcleo de $m$ preços, em que $m$ $<k$, testando-se o número de vetores de co-integração $(r)$. Se $r$ for igual a $(m-1)$, adiciona-se outra série e testa-se novamente. Os testes continuam até que todas as localidades sejam inseridas.

A participação de cada uma das localidades no espaço de co-integração é realizada pelo teste de razão de verossimilhança $(L R)$ :

$$
L R=2[\ln (L)-\ln (L *)] \sim \chi_{m}^{2},
$$

em que $\ln (L)$ é o logaritmo natural do valor da função de verossimilhança irrestrita; $\ln \left(L^{*}\right)$, logaritmo natural da função de verossimilhança com as restrições impostas pela hipótese nula; e $\chi_{m}^{2}$, valores críticos da

$(k-1$ listribuição de qui-quadrado com $m$ graus de liberdade ( $m$ é o número de restrições impostas pela hipótese nula), aos quais o valor de $L R$ deve ser comparado.

\subsection{Fonte e tratamento dos dados}

Foram utilizadas séries de preços recebidos pelos produtores do Brasil (BR), Vietnã (VT), Indonésia (ID) e Índia (IN) e, como proxy para o preço no mercado internacional ou nos mercados consumidores, foi usado o indicador de preços relativo ao tipo robusta (PI), da International Coffee Organization (ICO). As séries, com periodicidade mensal e cotadas em centavos de dólar por libra-peso, foram obtidas diretamente da home-page da ICO (www.ico.org). As séries foram transformadas em dólares por sacas de 60 quilos e, para atender às exigências do modelo analítico, também logaritmizadas. 
O período de análise foi compreendido entre 1988 e 2005. O início da série foi escolhido por ser imediatamente anterior à fase de crescimento acelerado da produção e exportação vietnamita e o último ano, por causa da indisponibilidade de dados mais recentes ${ }^{8}$. Acredita-se que esse período relativamente longo seja representativo das mudanças no mercado de café robusta que motivaram o presente estudo.

\section{Resultados e discussão}

Embora não haja comércio expressivo de café robusta entre os países produtores e exportadores considerados nesta análise, é plausível admitir que façam parte de um sistema único de comércio, já que são conectados indiretamente por meio de importadores comuns. Por exemplo, os principais destinos das exportações brasileiras e vietnamitas são Alemanha ( $20 \%$ e $15 \%$, respectivamente), EUA (18\% e 12\%), Itália (11\% e $8 \%$ ) e Japão (9\% e 4\%); da Indonésia, para os EUA, 21\%; Japão e Alemanha, com $16 \%$ cada um; e Itália, com $6 \%$. Esse último país é o maior comprador da Índia (25\%), seguido da Rússia (11\%) e Alemanha (9\%) (Usda, 2007).

Dessa forma, os mercados consumidores funcionariam como o elo entre os países, podendo ser a via pela qual choques de oferta e, ou, demanda numa localidade são transmitidos às demais. Portanto, primeiramente uma inspeção visual dos dados foi realizada para verificar a evolução dos preços em análise (Figura 2).

\footnotetext{
8 Até o momento da redação deste artigo, não havia dados de preço relativos ao Vietnã, para os anos de 2006 ou 2007. Segundo o setor de estatísticas da ICO, esses preços ainda não tinham sido encaminhadas pelo órgão responsável daquele país.
} 
Dênis Antônio da Cunha, Marcelo José Braga,

Antônio Carvalho Campos \& Luciany Lima Fernandes

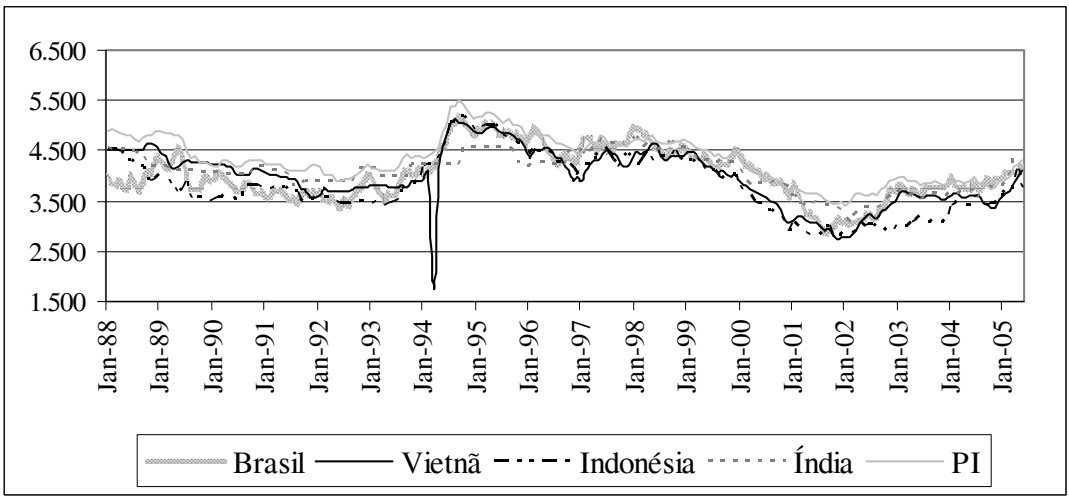

Figura 2 - Preços ao produtor de café robusta do Brasil, Vietnã, Indonésia, Índia e preço no mercado internacional, em US\$/ sacas $60 \mathrm{~kg}$, de 1988/1 a 2005/5, em logaritmo.

Fonte: ICO (2007).

No entanto, a análise visual somente indicou evolução semelhante de preços, o que não é suficiente para concluir que há tendência única de comportamento, no longo prazo. Procedeu-se, então, ao teste de estacionaridade de Dickey-Fuller (ADF), conforme descrito por Enders (1995) e, no caso do Vietnã, também foi realizado o teste de raiz unitária, com quebra estrutural de Perron (1989), devido ao valor discrepante observado em março de 1994.

A metodologia adotada neste trabalho exige que as séries tenham a mesma ordem de integração. Na Tabela $1^{\mathrm{A}}$, do Anexo, encontram-se os resultados obtidos, que indicaram que a série do preço internacional de café robusta e dos preços pagos aos produtores do Brasil, Vietnã, Indonésia e Índia, no período de 1988 a 2005, é integrada de mesma ordem, especificamente, $\mathrm{I}(1)$.

Procedeu-se, em seguida, ao teste de co-integração pelo procedimento de Johansen, a partir de um modelo VAR. Na escolha das defasagens foram observados os critérios de Akaike (AIC), Schwartz (SC) e Hannam-Quin (HQ), que indicaram, respectivamente, a inclusão de oito, 
uma e duas defasagens. Optou-se, então, pela inclusão de apenas uma defasagem no modelo pois, segundo Enders (1995), o critério SC é o mais parcimonioso e deve ser utilizado em casos de divergências nos resultados dos demais. A especificação do VEC e das equações de cointegração foi realizada com um modelo sem tendência determinística nos dados, com intercepto e sem tendência na equação de co-integração, e foi incluída uma variável $d u m m y^{9}$ na estimação para eliminar o efeito da observação discrepante observada na série no Vietnã, em março de 1994.

O teste foi realizado para as cinco séries conjuntamente e indicou a existência de apenas dois vetores de co-integração, evidenciando que uma ou mais séries deveriam ser excluídas do sistema. Implementou-se, então, o procedimento de exclusão seqüencial descrito na metodologia, considerando diferentes ordenações, optando-se, ao fim, pela exclusão da Índia. Com a retirada desse país, foram obtidos três vetores de cointegração (Tabela 1).

Tabela 1 - Teste de Johansen para identificação do número de relações de co-integração entre as séries de preços em análise, 1988/ 1 a $2005 / 5$

\begin{tabular}{lllll}
\hline Hipótese nula & $\mathbf{T}_{\text {trace }}$ & Valor crítico* $^{*}$ & $\boldsymbol{\tau}_{\max }$ & Valor crítico** $^{* *}$ \\
\hline $\mathrm{r}=0$ & $228.7672^{\mathrm{RH} 0}$ & 50.5253 & $187.3852^{\mathrm{RH} 0}$ & 28.5881 \\
$\mathrm{r} \leq 1$ & $41.3820^{\mathrm{RH} 0}$ & 32.2684 & $23.3264^{\mathrm{RH} 0}$ & 22.2996 \\
$\mathrm{r} \leq 2$ & $18.0557^{\mathrm{RH} 0}$ & 17.9804 & $16.2069^{\mathrm{RH} 0}$ & 15.8921 \\
$\mathrm{r} \leq 3$ & 1.8488 & 7.5567 & 1.8488 & 9.1645 \\
\hline
\end{tabular}

Fonte: Dados da pesquisa.

$(* *)$ e (*) referem-se aos valores críticos a 5\% e $10 \%$ de significância; $\mathrm{RH}_{0}$ indica a rejeição da hipótese nula.

9 A dummy incluída é do tipo pulse, que tem valor igual à unidade, no momento da ocorrência da observação discrepante $(T)$, e zero, nos demais períodos; 
Dênis Antônio da Cunha, Marcelo José Braga,

Antônio Carvalho Campos \& Luciany Lima Fernandes

Com base na Tabela 1, pôde-se concluir que os preços eram co-integrados e possuíam três relações de co-integração estatisticamente significativas a 10\% de significância, pelo teste do traço, e a 5\%, pelo teste do máximo auto-valor. Constatou-se, portanto, a existência de apenas uma tendência de comportamento no longo prazo entre os preços de café robusta, ou seja, esses mercados são eficientes na difusão de informações.

Por um lado, o fato de os preços da Índia não compartilharem a mesma tendência comum das demais séries deve ser interpretado com cautela. Devido à ausência de uma série de custos de transação no comércio internacional de café robusta, a não participação desse país no espaço de co-integração pode indicar não-estacionaridade de tais custos ${ }^{10}$, por outro, a ausência de integração pode ser explicada por características próprias da produção de café indiana. De acordo com Saes e Miranda (2007b), na Índia o governo atua de modo intenso para manter a população no campo, sendo a cafeicultura uma das atividades mais importantes e mais promovidas pelo Estado. Dessa forma, embora tenham sido feitas algumas reformas nos últimos anos, o setor cafeeiro nesse país ainda é marcado por profundo controle estatal e por protecionismo, o que, a rigor, comprometeria sua integração.

Para confirmar a presença das séries de preços no vetor de co-integração, foram realizados testes de razão de verossimilhança para restrições relacionadas com parâmetros $\beta$ e $\alpha^{11}$ (Tabela 2).

Todas as restrições relativas aos parâmetros $\beta$ foram rejeitadas a $1 \%$ de significância, o que indica que as quatro séries participavam, efetivamente, do equilíbrio de longo prazo do mercado internacional de café robusta, no período de 1988/1 a 2005/5.

\footnotetext{
${ }^{10}$ Goodwin (1992) apresenta um exemplo empírico no qual a co-integração entre os mercados internacionais de trigo somente é obtida quando os custos de transporte são incluídos na análise.

${ }^{11}$ As hipóteses nulas testadas foram $\mathrm{H}: \beta=0$ e $\mathrm{H}: \alpha,=0$, em que cada $i$ é uma das as três relações de cointegração e $k$ refere-se a cada uma das séries consideradas.
} 
Tabela 2 - Teste de razão de verossimilhança de restrições aos parâmetros de co-integração (â's) e de ajustamento (á's) relacionados com cada um dos preços que compõem o espaço de co-integração, 1988/1 a 2005/5

\begin{tabular}{lllll}
\hline & $\chi^{2}\left(\mathrm{H}_{0}: \beta\right.$ 's $\left.=0\right)$ & P-valor & $\chi^{2}\left(\mathrm{H}_{0}: \alpha\right.$ 's $\left.=0\right)$ & P-valor \\
\hline $\mathrm{PI}=0$ & 72,6183 & 0,0000 & 9,0785 & 0,0283 \\
$\mathrm{ID}=0$ & 26,4322 & 0,0000 & 6,2574 & 0,0997 \\
$\mathrm{BR}=0$ & 14,9462 & 0,0019 & 9,9001 & 0,0194 \\
$\mathrm{VI}=0$ & 182,9365 & 0,0000 & 164,8752 & 0,0000 \\
\hline
\end{tabular}

Fonte: Dados da pesquisa.

Em relação à matriz $\alpha$, o preço internacional e o do Brasil foram significativos a 5\% e o do Vietnã, a 1\%. No caso da Indonésia, a hipótese nula de $\alpha=0$ só pôde ser rejeitada a $10 \%$. Ainda assim, esse país foi mantido (as análises seguintes confirmam sua participação no equilíbrio do sistema no curto e longo prazo).

Considerou-se, portanto, que todos os mercados se ajustaram a desequilíbrios transitórios.

A avaliação da interdependência dos demais preços, considerando suas relações de longo prazo, foi realizada pelo modelo VEC, conforme especificado na equação (5). Estimaram-se relações de co-integração, normalizadas em relação ao Vietnã, escolha que se deve ao fato de ser este o maior produtor e exportador de café robusta. Conforme Mehta e Chavas (2008), é comum que mudanças na oferta desse país sejam responsáveis por variações no preço internacional. 
Dênis Antônio da Cunha, Marcelo José Braga,

Antônio Carvalho Campos \& Luciany Lima Fernandes

Tabela 3 - Vetores de co-integração ( $\beta$ 's), para o logaritmo das séries mensais de preços de café utilizadas no estudo, de 1988/1 a $2005 / 5$

\begin{tabular}{lccc}
\hline & PI & ID & BR \\
\hline VT & $-0,8926$ & $-1,1555$ & $-0,9912$ \\
& $(-38,5917)$ & $(-17,2231)$ & $(-7,8089)$ \\
\hline Constante & $-0,7591$ & 0,7857 & $-0,1255$ \\
& $(-8,1676)$ & $(2,9147)$ & $(-0,2467)$ \\
\hline
\end{tabular}

Fonte: Dados da pesquisa.

Nota: Os valores entre parênteses referem-se às estatísticas do teste $t$-Student. Valores críticos: $(* * *) 1 \%: 2,576 ;(* *) 5 \%: 1,960 ;(*) 10 \%: 1,645$.

A Tabela 3 mostra as três relações de equilíbrio no longo prazo, no período de janeiro de 1988 a maio de 2005, entre os pares de preços (Preço Internacional e Vietnã; Indonésia e Vietnã; e Brasil e Vietnã), que também podem ser escritas como:

$p_{P I, t}=0,7591+0,8926 p_{V T, t} ; p_{I D, t}=-0,7857+1,1555 p_{V T, t} ; p_{B R, t}=0,1255+0,9912 p_{V T, t}$.

Os parâmetros $\beta$ 's foram individualmente significativos a $1 \%$, o que confirma a integração entre esses mercados. As elasticidades de transmissão de preços de longo prazo foram relativamente altas - uma variação de $10 \%$ nos preços do Vietnã causaria uma mudança, no mesmo sentido, de 8,9\% nos preços internacionais, de $11,5 \%$ nos preços da Indonésia e de 9,9\% nos preços do Brasil. A maior influência do Vietnã sobre a Indonésia pode ser atribuída à proximidade geográfica dessas localidades, em relação ao Brasil, e também ao fato de a Indonésia importar café verde do Vietnã (corresponde a cerca de 3\% das exportações desse país, segundo dados do USDA, 2007).

Resultados significativos de transmissão de preços no mercado internacional, semelhantes aos deste estudo, em que se utilizou o modelo de co-integração, foram obtidos por Costa e Ferreira Filho (2000), que 
estudaram a integração entre os principais exportadores de milho e arroz; por Coelho (2004), para os mercados de algodão; e por Jarvis et al. (2005), na análise dos preços de carne.

Essa integração entre os principais mercados internacionais de café robusta pode ser explicada, de acordo com considerações de Nogueira (2005), pelos recentes desenvolvimentos tecnológicos nas áreas de telecomunicações e informática, entre outros, que permitem rápida difusão de informações entre os diversos participantes do mercado de café. Nesse contexto, a bolsa de Londres, NYSE EURONEXT, tem grande importância, pois possibilita ampla e rápida divulgação de preços que norteia as decisões dos agentes sobre produção, comercialização e estocagem.

A Tabela 4 apresenta informações sobre a estrutura espacial do mercado e a velocidade do ajustamento a desequilíbrios transitórios (matriz $\alpha$ ).

Tabela 4 - Coeficientes de ajustamento ( $\alpha$ 's) do VEC irrestrito, para o logaritmo das séries mensais de preços de café utilizadas no estudo, de 1988/1 a 2005/5

\begin{tabular}{lcccc}
\hline Correção de erros & PI & ID & BR & VT \\
\hline (PI, VT) & $\mathbf{- 0 , 1 0 2 2}$ & $\mathbf{0 , 1 0 5 1}$ & $-0,0306$ & $\mathbf{0 , 5 0 3 6}$ \\
& $(-2,3792)$ & $(1,7052)$ & $(-0,4643)$ & $(6,8858)$ \\
(ID, VT) & $\mathbf{0 , 0 8 4 3}$ & $\mathbf{- 0 , 0 9 1 1}$ & $\mathbf{0 , 1 0 7 3}$ & $\mathbf{0 , 1 4 9 5}$ \\
& $(2,9502)$ & $(-2,2255)$ & $(2,4426)$ & $(3,0824)$ \\
(BR, VT) & $-0,0003$ & 0,0442 & $\mathbf{- 0 , 0 8 8 1}$ & $-0,0019$ \\
& $(-0,0123)$ & $(1,5874)$ & $(-2,9510)$ & $(-0,0567)$ \\
\hline
\end{tabular}

Fonte: Dados da pesquisa.

Nota: Os valores entre parênteses referem-se às estatísticas do teste $t$-Student. Valores críticos: $(* * *) 1 \%: 2,576 ;(* *) 5 \%: 1,960 ;(*)$ 10\%: 1,645 . 
Dênis Antônio da Cunha, Marcelo José Braga,

Antônio Carvalho Campos \& Luciany Lima Fernandes

Entre os mercados analisados, como mostra a Tabela 4, o preço da Indonésia foi o mais interdependente, pois os demais se ajustaram significativamente aos seus desequilíbrios. Além disso, alterações no preço internacional foram sentidas no mercado indonésio. Tal interdependência confirma a participação desse país no espaço de co-integração. O Brasil apresentou a menor interdependência, já que alterações nos seus preços somente influenciaram eles próprios. O preço internacional ficou numa posição intermediária, tendo causado mudanças, de modo significativo, na Indonésia e no Vietnã. Os preços deste último são os que responderam mais rapidamente aos choques, com coeficientes de 0,5036 , em relação ao preço internacional, e de 0,1495 , relativos ao preço da Indonésia.

Por um lado, esses resultados eram esperados, pois a maior parte da produção brasileira refere-se à espécie arábica e o país não exerce muita influência no mercado de café verde robusta; por outro, Vietnã e Indonésia, além da proximidade geográfica, são muito competitivos no setor, devido, principalmente, aos baixos preços de seu produto. Ainda assim, deve-se mencionar que o Brasil tem uma indústria de café solúvel relativamente desenvolvida, que é, em grande parte, voltada para o mercado externo ${ }^{12}$.

Com base nos estudos de May et al. (2004) e Mehta e Chavas (2008), esse padrão de integração, em que não há interdependência de todos os preços, pode ser explicado pelo fato de muitos pequenos produtores estarem em regiões remotas. O caso do Vietnã deve ser destacado, já que toda a sua produção é realizada em pequenas propriedades, e o país apresenta precária infra-estrutura de comunicação, transporte e logística. A dificuldade de acesso aos mercados reduz a habilidade dos produtores para negociarem com outros participantes da cadeia produtiva, o que impede uma resposta adequada às condições de mercado no curto prazo. 
Outra explicação para a não completa interdependência é que existem grandes impedimentos às importações de café verde pelos países em estudo. Em geral, os produtores temem que a entrada do produto de outros países possa comprometer a produção e os preços domésticos. Por um lado, o Brasil, por exemplo, dificulta a importação de café verde robusta, sobretudo proveniente do Vietnã, por meio de restrições fitossanitárias, justificando que se deve evitar a entrada de pragas e doenças comuns na lavoura daquele país. Por outro, a Indonésia adquire café robusta do Vietnã para a reexportação; o produto importado é misturado às variedades locais e revendido como sendo de qualidade superior (Usda, 2007).

Embora a análise tenha indicado integração entre o preço internacional e o do Brasil, Vietnã e Indonésia, não se pode falar numa perfeita integração entre esses mercados, ou seja, a existência de vetores de co-integração do tipo $(1,-1)$. A Tabela 5 contém os resultados do teste de razão de verossimilhança para a hipótese de perfeita integração.

Tabela 5 - Teste de razão de verossimilhança para verificação da hipótese de perfeita integração entre pares de preços

$$
\begin{aligned}
& \mathrm{H}_{0} \\
& \hline \beta_{\mathrm{PI}}=-\beta_{\mathrm{VI}} \\
& \beta_{\mathrm{ID}}=-\beta_{\mathrm{VI}} \\
& \beta_{\mathrm{BR}}=-\beta_{\mathrm{V}}
\end{aligned}
$$

Fonte: Dados da pesquisa.

Rejeitou-se a perfeita integração para os três pares de mercado. Tal constatação é plausível na medida em que os vetores de co-integração, conforme análise de González-Rivera e Helfand (2001), captam diferenças de sistemas produtivos, tecnologias e qualidade do produto. A produção 
Dênis Antônio da Cunha, Marcelo José Braga,

Antônio Carvalho Campos \& Luciany Lima Fernandes

de café nos países considerados é bastante heterogênea; já não há intervenção governamental no setor cafeeiro do Brasil, realidade ainda não totalmente assegurada nos demais; por fim, as diferenças entre os parâmetros estimados podem ser resultado de custos de transação relacionados com fretes, taxas portuárias, entre outros custos de comercialização, específicos de cada país.

A ausência de perfeita integração é comum na literatura, uma vez que requer que o mercado funcione em condições muito próximas às de concorrência perfeita. Esta é uma das críticas que são feitas às análises fundamentadas exclusivamente na Lei do Preço Único. No estudo da integração entre os estados produtores de café brasileiros, realizado por Nogueira (2005), essa hipótese foi igualmente rejeitada. Em outros trabalhos, como o de Pereira (2005) e Rosado (2006), que tratam da integração entre os mercados, respectivamente, de boi gordo e suínos do Brasil, as conclusões são semelhantes.

De modo geral, os resultados obtidos estão relacionados com características do mercado de café. O comércio externo do tipo robusta tem crescido, entre outros motivos, pelo controle exercido pelas principais empresas do setor, tais como Nestlé, Sara Lee, Starbucks e KraftFoods. Essas companhias atuam nos vários países, controlam o "sabor" da bebida nos mercados consumidores e combinam essa variedade com o tipo arábica na confecção de seus blends. Dessa forma, o fato de poucas firmas controlarem o mercado internacional de café, comprando o produto de vários países e, possivelmente, aplicando políticas semelhantes, faz com que haja co-movimento de preços. Essa transmissão de preços, mesmo indireta, é a própria definição de integração de mercados. Goodwin e Schroeder (1991) encontraram evidência desse tipo de relacionamento, ao concluírem que a maior integração do mercado de carne bovina dos Estados Unidos foi resultado da concentração na indústria processadora. 


\section{Conclusão}

Neste estudo procurou-se analisar a integração entre o preço internacional de café robusta e o preço dos quatro maiores países exportadores dessa commodity - Brasil, Indonésia, Índia e Vietnã. Testou-se a hipótese de que este último país era importante na transmissão de preços entre os mercados considerados.

Pelos resultados obtidos, verificou-se que os preços internos no Vietnã, Brasil, Indonésia e o preço externo apresentam relação de equilíbrio no longo prazo, sendo, portanto, integrados. Dessa forma, choques de preços num mercado seriam transmitidos aos demais. Esse é um indício de que o mercado internacional de café robusta está funcionando corretamente, sendo eficiente na difusão de informações. Apesar da integração, verificou-se que cada país respondeu, de modo mais significativo, aos seus próprios desequilíbrios.

A Indonésia, que é o terceiro maior exportador de café robusta, foi a localidade mais interdependente do sistema, o que contraria a hipótese, inicialmente proposta, de que o Vietnã desempenharia esse papel. Acredita-se que as dificuldades ligadas à infra-estrutura de escoamento da produção e ao acesso às informações de mercado que esse último país enfrenta tenham sido responsáveis por tal resultado. No entanto, a posição claramente secundária do Brasil nesse mercado foi confirmada.

O fato de as importações de café serem dominadas por poucos grandes grupos empresariais pode ter contribuído para a transmissão de preços entre os mercados. As companhias, ao adquirir o produto de vários países, podem fazer com que movimentos semelhantes de preços ocorram.

Não foi constatada perfeita integração entre os mercados, o que faz sentido quando são consideradas as diferenças e a distância geográfica entre as regiões. Identificou-se, ainda, que o preço da Índia é influenciado por fatores que não são comuns aos demais países. 
Finalmente, a revolução tecnológica que vem se desenvolvendo nos últimos anos tem grande responsabilidade sobre esses resultados. As informações, principalmente sobre preços, são repassadas aos agentes da cadeia produtiva de maneira muito eficiente e rápida. Deve-se destacar também a maior utilização dos mercados futuros e de opções por parte dos players que atuam no setor, sendo a bolsa de Londres referência mundial nessas negociações.

\section{Referências}

COELHO, A. B. A Cultura do Algodão e a Questão da Integração entre Preços Internos e Externos. Revista de Economia e Sociologia Rural, v. 42, n. 01, p. 153-169, 2004.

COSTA, S. M. A. L.; FERREIRA FILHO, J. B. S. Liberalização comercial no Brasil e integração no mercado de commodities agrícolas: os mercados de algodão, milho e arroz. Revista Brasileira de Economia e Sociologia Rural, v. 38, n. 2, p. 41-70, 2000.

ENDERS, W. Applied econometric time series. New York: John Wiley, 1995. 433p.

FACKLER, P.L.; GOODWIN, B.K. Spatial price analysis. IN: RAUSSER, G. C.; GARDEN, B. L. (ed.). Handbook of Agricultural Economics. North-Holland Press, p. 971-1024, 2001.

FAMINOW, M. D.; BENSON, B. L. Integration of spatial markets. American Journal of Agricultural Economics, v. 72, n. 1, p. 49-62, feb. 1990.

GONZÁLEZ-RIVERA, G.; HELFAND, S. M. The extent, pattern and degree of market integration: a multivariate approach for the Brazilian rice market. American Journal of Agricultural Economics, v. 83, n. 3, p. 576-592, aug. 2001. 
GOODWIN, B. K. Multivariate cointegration tests and the law of one price in international wheat markets. Review of Agricultural Economics, v. 14, n. 1 p. 117-124, 1992.

GOODWIN, B. K.; SCHROEDER, T. C. Cointegration tests and spacial price linkages in regional cattle markets. American Journal of Agricultural Economics, v. 73, n. 2, p. 452-464, 1991.

INTERNATIONAL COFFEE ORGANIZATION - ICO. Historical Data. Disponível em: $<$ http://www.ico.org/asp/select7.asp $>$, Acesso em: jan./2007.

JARVIS, L.S.; BERVEJILLO, J.E.; CANCINO, J.P. International beef prices: is there evidence of convergence? Review of Agricultural Economics, v. 27 n.3, p. 449-455, 2005.

JOHANSEN, S. Statistical analysis of cointegration vectors. Journal of Economics Dynamics \& Control, v. 12, p. 231-254, 1988.

JOHANSEN, S. Estimation and hypothesis testing of cointegration vectors in Gaussian vector autoregressive models. Econometrica, v. 59, p. 15511580, 1991.

JOHANSEN, S., JUSELIUS, K. Maximum likelihood estimation and inference on cointegration - with application to the demand for money. Oxford Bulletin on Economics and Statistics, v. 52, n. 1, p. 169-210, 1990.

KRUGMAN, P.; R., OBSTFELD, M. Economia internacional: teoria e política. São Paulo: Pearson Addison Wesley, 2005.

MAY, P. H.; MASCARENHAS, G. C. C.; POTTS, J. Sustainable Coffee Trade: the role of coffee contracts. Winnipeg, Manitoba: International Institute for Sustainable Development, 2004. 63 p. Disponível em: $<$ http://www.iisd.org/pdf/2004/sci coffee contracts.pdf $>$.Acesso em $22 / 01 / 2008$. 
Dênis Antônio da Cunha, Marcelo José Braga,

Antônio Carvalho Campos \& Luciany Lima Fernandes

MEHTA, A.; CHAVAS, J. P. Responding to the coffee crisis: what can we learn from price dynamics? Journal of Development Economics, v. 85, n. 1-2, p. 282-311, 2008.

NOGUEIRA, F. T. P. Integração dos mercados internos e externos de café. 120 p. Tese (Doutorado em Economia Aplicada) - Universidade Federal de Viçosa, 2005.

PEREIRA, L. R. R. Integração espacial no mercado brasileiro de boi gordo. 166 p. Tese (Doutorado em Economia Aplicada) Universidade Federal de Viçosa, 2005.

PERRON, P. The great crash, the oil price shock and the unit root hypothesis. Econometrica, v. 57, n. 6, p. 1361-1401, 1989.

PONTE, S. (2001). The "latte revolution"? Winners and losers in the restructuring of the global coffee marketing chain. Working Paper 01.3, Centre for Development Research, Copenhagen, 2001. 35 p.

ROSADO, P. L. Integração espacial entre os mercados brasileiros de suínos. 117 p. Tese (Doutorado em Economia Aplicada) Universidade Federal de Viçosa, 2006.

SAES, M. S. M.; MIRANDA, B. V. Qualidade do café no Vietnã. Disponível em <http://www.cncafe.com.br/capa.asp?id=3112>. Acesso em: dez. 2007a.

SAES, M. S. M.; MIRANDA, B. V. Índia: oportunidades e desafios no gigante asiático. Disponível em < http://www.cncafe.com.br/ noticias_ler.asp? $\mathrm{id}=304 \& \mathrm{t}=3 \&$ counter $=22>$ Acesso em: dez. $2007 \mathrm{~b}$.

UNITED STATES DEPARTMENT OF AGRICULTURE - USDA. Tropical Products: coffee. Disponível em: <http://www.fas.usda.gov/ tropical_arc.asp>, Acesso em: jan. 2007. 


\begin{abstract}
The robusta coffee market has experienced changes which are characterized by a growth in the demand and the confirmation of Vietnam as the world's greater producer and exporter leaving behind traditional producers as Indonesia. These changes motivated the analysis of international price integration and the main markets of this commodity: Vietnam, Brazil, Indonesia and India. It was tested the hypothesis that Vietnam transmits prices shocks to the other markets. The framework used the analysis of co-integration and the Vector Error Correction (VEC) model. It was shown that, in the period from 1988 to 2005, the foreign price and the ones from Vietnam, Brazil and Indonesia were integrated and the India's price was affected by factors that are not common to the other countries. There was no perfect integration and Vietnam, although important, wasn't the more interdependent market.
\end{abstract}

Keywords: Robusta coffee, price transmission, market integration, VEC. 
Dênis Antônio da Cunha, Marcelo José Braga,

Antônio Carvalho Campos \& Luciany Lima Fernandes

\section{Anexo: Resultados dos testes de estacionaridade}

Tabela 1A - Teste de estacionariedade para o logaritmo das séries mensais de preços de café utilizadas no estudo, de 1988/1 a 2005/5, em nível e primeira diferença

\begin{tabular}{lccc}
\hline Série & Defasagens & Estatística de teste* $^{*}$ & Conclusão \\
\hline Séries em nível & & & \\
\hline BR & 1 & $-1,9263^{\mathrm{NR}}$ & Não-estacionária \\
VT & 1 & $-2,4142^{\mathrm{NR}}$ & Não-estacionária \\
VT** & 1 & $-1,9118^{\mathrm{NR}}$ & Não-estacionária \\
ID & 0 & $-1,5614^{\mathrm{NR}}$ & Não-estacionária \\
IN & 1 & $-1,8567^{\mathrm{NR}}$ & Não-estacionária \\
PI & 1 & $-1,8384^{\mathrm{NR}}$ & Não-estacionária \\
\hline Séries em primeira diferença & & \\
\hline BR & 0 & $-11,9883$ & Estacionária \\
VT & 0 & $-20,6220$ & Estacionária \\
ID & 0 & $-13,7814$ & Estacionária \\
IN & 0 & $-12,1766$ & Estacionária \\
PI & 0 & $-10,6698$ & Estacionária \\
\hline
\end{tabular}

Fonte: Dados da pesquisa.

(*) Foi incluída uma constante na equação de teste. $(* *)$ Teste de Perron (1989) (a dummy do tipo pulse incluída assumiu valor 1 em 1994/3 e 0 nos demais meses; $N R$ indica não rejeição de $H_{0}$ [os valores críticos de MacKinnon (1996) a $1 \%, 5 \%$ e $10 \%$ são, respectivamente, $-3,47 ;-2,88 ;$ e $-2,58]$. 
REVISTA DE ECONOMIA E AGRONEGÓCIO, VOL.6, $N^{o} 1$ 